\title{
ESTILOS DE LIDERANÇA DA ENFERMEIRA NUMA INSTITUIÇÃO PÚBLICA DE FORTALEZA
}

\author{
LEADERSHIP STYLES OF NURSES IN A PUBLIC INSTITUTION IN \\ FORTALEZA \\ ESTILOS DE LIDERAZGO EN UNA INSTITUCIÓN PÚBLICA DE \\ FORTALEZA
}

\author{
Eucléa Gomes Vale ${ }^{1}$ \\ Francisca Heronildes Patricio Caetano ${ }^{2}$ \\ Marta Maria Girão Carneiro ${ }^{3}$ \\ Maria Goretti Coelho Sampaio ${ }^{4}$
}

\begin{abstract}
RESUMO: Nas organizações modernas a liderança tem tido muita ênfase, por ser considerada um processo fundamental na consecução dos objetivos da empresa. É através dela que se desenvolve a habilidade de influenciar o comportamento das pessoas, facilitando-lhes a realização das atividades desejadas. O estudo objetiva investigar a liderança da enfermeira chefe, considerando as opiniöes das enfermeiras assistenciais em quatro unidades de um hospital público. O estudo revelou que as enfermeiras, em cargos de chefia, apresentam estilo de liderança centrado no serviço e nas pessoas.
\end{abstract}

PALAVRAS-CHAVE: gerência, liderança na enfermagem

\section{INTRODUÇÃO}

Nas organizações modernas, o estilo de liderança tem tido muita ênfase por se constituir um processo fundamental na consecução dos objetivos da empresa, pois é através dela que a pessoa desenvolve a habilidade de influenciar o comportamento de outras, facilitando-lhes a realização de atividades desejadas.

O estilo gerencial proposto por Black e Mouton (1995), apontam para um conjunto de valores e crenças apresentados pelos gerentes onde as preocupações básicas estão dirigidas às pessoas e à produção, ao mesmo tempo.

A preocupação com as pessoas diz respeito ao como e o quanto a satisfação, o desenvolvimento, a proteção e a relação entre os subordinados têm importância para o gerente e influencia na sua forma de agir junto à equipe.

Nessa perspectiva, existem os gerentes cuja única preocupação com as pessoas é saber se essas estão em seus postos de trabalho. Esta falta de atenção para com as pessoas pode ter múltiplos significados para o gerente, mas, de qualquer forma, sempre conduzem à

${ }^{\prime}$ Enfermeira, Mestre em Educação, Professora do Curso de Enfermagem da UECE (Universidade Estadual do Ceará). Diretora da Divisão Técnica do Hospital Geral de Fortaleza/SESAV SUS.

${ }^{2}$ Enfermeira, Livre Docente em Administração em Enfermagem, Professora do Curso de Enfermagem da UECE (Universidade Estadual do Ceará). Bolsista/FUNCAP.

${ }^{3}$ Enfermeira, Especialista em Enfermagem Pediátrica e Neonatal, Chefe do Setor de Neonatologia do Hospital Geral de Fortaleza/SESA/SUS.

${ }^{4}$ Enfermeira, Chefe do Setor de Endoscopia do Hospital Geral de Fortaleza//SESAVSUS. 
administração de sua área de trabalho, "apesar" das pessoas que fazem parte dela.

Por outro lado, existem gerentes que dispensam atenção a sua equipe de trabalho. Porém, pode-se intuir diferentes significados e consequeências para a qualidade das ações desenvolvidas pelo grupo. Nesse sentido, a gerência existe com a finalidade de dinamizar as atividades que o individuo não pode fazer sozinho e precisa compartilhar com outros como uma ação coletiva direcionada para uma meta comum.

Consoante Mota (1994, p. 37) gerenciar constitui o exercicio de uma atividade que:

"exige mais de uma pessoa para exercê-la";

"existe um objetivo comum";

"requer uma ação calculada (...) para alcançar os fins";

"necessita de cooperação e coordenação entre individuos, para que um não atue em detrimento ou oposiçâo ao outro".

Os Sistemas Organizacionais preconizados por Likert (1995), concebem que a empresa pode funcionar em qualquer um dos pontos do continuo de quatro sistemas. No Sistema l está o autoritário - forte, onde o executivo administra com mão-de-ferro, - "Chefe - Chefe"- cujas decisões são tomadas na alta gerência, sem "feed-back" para os demais. O autoritário benevolente, está classificado no Sistema II, embora haja semelhança com o estilo autoritário - forte do Sistema I, porém neste o executivo se apresenta mais sensivel às necessidades do trabalhador. O estilo consultivo, classificado no Sistema III, mantém as figuras de autoridade e controle, todavia buscam consultar os niveis inferiores. O quarto e último sistema, caracterizado como grupo participativo, permite ao trabalhador das várias camadas de execução dentro da empresa compartilhar do cotidiano de tomadas de decisōes institucionais. Esse sistema se constitui num modelo considerado ideal, por ser o mais produtivo, impondo a criação de uma co-responsabilidade, que sem dúvida aflora uma maior motivação para o trabalho. Esse sistema exige uma alta qualificação dos profissionais da empresa.

O propósito do estudo em apreço é investigar o estilo de liderança exercido pelas enfermeiras, em cargos de chefia, considerando as opiniőes e percepçőes que as enfermeiras assistenciais mantém nas relações de trabalho nas unidades delimitadas.

\section{TRAJETÓRIA METODOLÓGICA}

Esta pesquisa foi realizada num Hospital Geral de referência terciária da Rede Pública Estadual do municipio de Fortaleza, tendo como locus do estudo, constituiu-se de quatro unidades de serviço, quais sejam: Unidade de Pronto Atendimento (Emergência), Unidade de Ambulatório, Unidade de Internação Médico-Cirúrgica e Unidade de Terapia Intensiva.

O universo estudado foi constituido de enfermeiras assistenciais lotadas nas referidas unidades e o grupo amostral constou de 53 enfermeiras. Das 10 enfermeiras que não participaram do estudo 4 estavam de férias, 2 de licença de saúde e 4 foram excluidas da amostra por terem pouco contato com a chefia.

$\mathrm{O}$ instrumento para coletar os dados foi um questionário estruturado, cujos itens permitissem a emissão de opiniões, reflexōes e, posicionamentos relacionados com as situaçōes vivenciadas no cotidiano do processo de trabalho nas unidades, na perspectiva de identificar os estilos de lideranças visualizados pelo grupo pesquisado e que passou por um teste piloto para a sua validação.

O levantamento dos dados foi realizado pelas autoras no periodo de 10 de fevereiro a 30 de março de 1998.

$\mathrm{Na}$ apresentação e discussão dos resultados da pesquisa utilizam-se uma abordagem descritiva e analitica com base na interpretação dos pesquisadores e com o respaldo teórico dos outros autores que abordaram essa temática. A seguir foi efetuada uma análise qualitativa sobre as percepções das enfermeiras assistenciais acerca dos estilos de liderança adotados 
pelas enfermeiras chefes dos setores.

Na distribuição da amostra, verificou-se que o tempo de conclusão do curso de enfermagem entre as pesquisadas variou de 02 a 18 anos e, o tempo de trabalho na instituição teve uma variação de 10 meses a 22 anos.

\section{APRESENTAÇĀO EANÁLISE DOS RESULTADOS}

Quando se desejou saber qual o nivel de confiança do chefe para com a equipe, constatou-se que $41(96,3 \%)$ das enfermeiras lotadas nas unidades estudadas, estão satisfeitas com o nivel de confiança que a chefe deposita nelas.

Perguntou-se, então, se o chefe aceita sugestões quando são tomadas as decisões e quando se dá o estabelecimento de metas.

Os dados mostraram que $26(60 \%)$ apontam que a chefe busca sugestões; e 25 (58\%) demostraram que a tomada de decisão sempre ocorre com a participaçăo efetiva da equipe.

Observou-se que $23(53,4 \%)$ das enfermeiras afirmaram que a chefe estabelece metas junto com a equipe execeto em situaçōes de crise, o que evidencia a importância do estabelecimento de metas para eficácia da produtividade no processo de trabalho da enfermagem.

De acordo com Nadler et al. (1990) o estabelecimento de metas define o que o serviço faz e assim fornece uma variável importante para o entendimento do comportamento organizacional ao determinar o propósito do serviço.

Questionando-se sobre a ịmagem que os liderados têm do seu lider, percebeu-se que no exercício da gerência é importante a imagem que os liderados têm de seu chefe. Nessa perspectiva, as participantes do estudo demostraram que as chefias dos setores apresentam estilos de liderança centradas no serviço e nas pessoas como revelado nos dados e falas a baixo:

Para $68,84 \%$ dos entrevistados, os chefes valorizam as pessoas por considerarem que estas são importantes e para o alcance dos objetivos do serviço e para o cumprimento da missão da Instituição.

As pessoas são a maior riqueza da empresa, por isso devem ser bem tratadas, proporcionando um clima de amizade e afeto.

A função do chefe é alcançar a instituição entre as pessoas e o trabalho para que possam produzir e sentirem-se bem.

Corraborando com a idéia Black e Mouton (1995, p.12) enfatizam que alguns lideres se destacam por assegurarem a estima dos subordinados. Outros se preocupam com a execução das tarefas. Nos dois casos "a conquista de resultados com base na confiança e no respeito, na obediência, na simpatia ou na compreensão e no apoio é manifestação de preocupação com as pessoas".

Quando questionadas sobre o controle exercido pela chefia $31,16 \%$ dos enfermeiros, afirmaram que o chefe exerce um controle efetivo sobre as açőes desenvolvidas.

Nas falas das pesquisadas revelou-se a existência de uma liderança dirigida para o controle como vemos nos depoimentos a seguir:

...limitando-se a transmitir ordens dos superiores.

Cobra muito, mas não ajuda em nada.

...garantir uma produção aceitável sem se incomodar com as pessoas.

Vale, finalmente, destacar que o exercício da liderança precisa conjugar a participação da equipe nas decisōes e metas, ao mesmo tempo que sejam asseguradas o cumprimento dos 
objetivos e a missão do Serviço de Enfermagem. Numa palavra, é preciso garantir eficácia, eficiência, efetividade e participação.

\section{CONSIDERAÇÖES FINAIS}

As enfermeiras, objeto do estudo, demonstram experiência profissional tanto pelo tempo de formada como pelo tempo de trabalho na instituição. Esse fato permitiu supor que as opiniōes e a percepçăo sobre o tema liderança tenha sido fruto do convivio cotidiano nas relações de trabalho junto às chefias estudadas.

Verificou-se um percentual significativo $(96,3 \%)$ de enfermeiras que, se declaram satisfeitas com o nivel de confiança que o chefe deposita nelas. Para (60\%) das respondentes o chefe busca sugestões no grupo. Esta conduta reflete uma valorização das idéias e do desempenho da equipe.

No desenvolvimento do processo de trabalho, $53,4 \%$ dos declarantes afirmam que a chefia elabora as metas discutindo com a equipe, exceto em situaçőes de crise, quando há exigência de um trabalho urgente relacionado a medidas que não podem ser agendadas previamente, possibilitando a participaçăo dos agentes.

O estudo revelou que as enfermeiras em cargos de chefia, apresentam estilo de liderança centrado no serviço e nas pessoas.

Reconhece-se que a temática é polêmica e, como tal, uma fonte inesgotável de novas descobertas, haja vista que a complexidade da função gerencial implica algumas atribuições básicas, tais como dirigir, organizar e controlar pessoas, ou seja, seu objeto de trabalho são os recursos humanos da instituição e o processo de produçăo de serviços.

ABSTRACT: In modern organizations leadership has been emphasized, since it is considered fundamental to the execution of the objectives of a company. It is through leadership that the ability of influencing the behavior of others is developed, facilitating the accomplishment of activities. The study has as its objective the investigation of the head nurse's leadership, considering the opinion of assistant nurses in four units of a public hospital. The study has shown that nurses who are in managerial position, present a leadership profile centered on the service and on individuals.

KEYWORDS: leadership, management, nursing leadership

RESUMEN: En las organizaciones modernas el liderazgo ha tenido mucho énfasis, pues se le considera un elemento fundamental para la consecución de los objetivos de la empresa. Por su intermedio se desenvuelve la habilidad de influir en el comportamiento de las personas y facilitarles la realización de las actividades que se pretenden. El estudio tiene como objetivo investigar el liderazgo de la enfermera jefa, considerando las opiniones de las enfermeras asistenciales en cuatro unidades de un hospital público. El estudio ha revelado que las enfermeras, en situación de cargo, presentan un estilo de liderazgo que se centra en el servicio y en las personas.

PALABRAS CLAVE: liderazgo, gestión, liderazgo en enfermeria

\section{REFERÊNCIAS BIBLIOGRÁFICAS}

NADLER, D.A et al. Comportamento Organizacional. Rio de Janeiro: Campus, 1995. 254 p. MOTA, P.R. Gestão Comtemporânea: a ciência e a arte de ser dirigente. 4. ed. Rio de Janeiro: RECORD, 1994. 256 p.

MOUTON, J.S; BLACK, R.R. O Grid Gerencial III: a chave para a liderança eficaz. 3. ed. São Paulo: Pioneira, 1995. 247 p.

Recebido em janeiro de 2000

Aprovado em fevereiro de 2001 